Edith Cowan University

Research Online

Research outputs 2014 to 2021

2021

\title{
Climate change, activism, and supporting the mental health of children and young people: Perspectives from Western Australia
}

Naomi J. Godden

Edith Cowan University

Brad M. Farrant

Jaime Yallup Farrant

Emma Heyink

Eva Carot Collins

See next page for additional authors

Follow this and additional works at: https://ro.ecu.edu.au/ecuworkspost2013

Part of the Environmental Sciences Commons, Psychology Commons, and the Sociology Commons

10.1111/jpc. 15649

Godden, N. J., Farrant, B. M., Yallup Farrant, J., Heyink, E., Carot Collins, E., Burgemeister, B., . . Cooper, T. (2021).

Climate change, activism, and supporting the mental health of children and young people: Perspectives from

Western Australia. Journal of Paediatrics and Child Health, 57(11), 1759-1764. https://doi.org/10.1111/jpc.15649

This Journal Article is posted at Research Online.

https://ro.ecu.edu.au/ecuworkspost2013/11560 


\section{Authors}

Naomi J. Godden, Brad M. Farrant, Jaime Yallup Farrant, Emma Heyink, Eva Carot Collins, Bella

Burgemeister, Mena Tabeshfar, Jason Barrow, Mara West, Jasmine Kieft, Mason Rothwell, Zoe Leviston,

Susan Bailey, Mindy Blaise, and Trudi Cooper 


\title{
Climate change, activism, and supporting the mental health of children and young people: Perspectives from Western Australia
}

\author{
Naomi J Godden (D), ${ }^{1,2}$ Brad M Farrant (1), Jaime Yallup Farrant (1), ${ }^{4}$ Emma Heyink, ${ }^{5}$ Eva Carot Collins, ${ }^{6}$ \\ Bella Burgemeister, ${ }^{7}$ Mena Tabeshfar, ${ }^{8}$ Jason Barrow, ${ }^{9}$ Mara West, ${ }^{3}$ Jasmine Kieft, ${ }^{4}$ Mason Rothwell $\left(10,{ }^{10}\right.$ \\ Zoe Leviston (1), ${ }^{11}$ Susan Bailey (1), ${ }^{12}$ Mindy Blaise (1) ${ }^{13}$ and Trudi Cooper (1) 14 \\ ${ }^{1}$ Centre for People, Place and Planet, Edith Cowan University, ${ }^{7}$ WA Youth Climate Activist, ${ }^{12}$ School of Arts and Humanities, Edith Cowan University, \\ Bunbury, ${ }^{3}$ Telethon Kids Institute, The University of Western Australia, ${ }^{4}$ Climate Justice Union, ${ }^{8}$ School Strike for Climate Activist, ${ }^{9} \mathrm{Ngalak}$ Katitjin, ${ }^{10}$ Youth \\ Affairs Council of Western Australia, ${ }^{13}$ Centre for People, Place and Planet, Edith Cowan University, ${ }^{14}$ School of Arts and Humanities, Edith Cowan \\ University, Perth, ${ }^{5}$ WA Youth Climate Activist, Margaret River, ${ }^{6}$ WA Youth Climate Activist, , Western Australia, ${ }^{2}$ Department of Social Work, Monash \\ University, Caulfield East, Victoria and ${ }^{11}$ Research School of Psychology, Australian National University, Canberra, Australian Capital Territory, Australia
}

\begin{abstract}
The climate crisis has detrimental impacts on the mental health and wellbeing of children and young people. Psychological effects include feelings of fear, overwhelm, worry, distress, hopelessness and anger; PTSD; depression; anxiety; phobias; panic disorder; sleep disturbances; attachment disorders; learning difficulties; substance abuse; shock and trauma symptoms; adjustment problems; behavioural problems; and, suicidal thinking. First Nations' children and young people are particularly at risk due to loss of place, identity, culture, land and customs informed by kinship relationships with the Earth; while sustainable land use practices and connection to Country and community can enhance climate resilience. In Western Australia (WA), some young people engage in climate activism - including striking from school - to demand government action to address the causes of climate change, including colonisation and capitalism. Climate activism can promote resilience, particularly when children and young people can emotionally engage in the climate crisis; when mental health is systemically supported; when climate communication is transparent and comprehensive; and, when activism is informed by the knowledges and wisdoms of First Nations peoples and grounded on Country. This article is co-authored by WA young people, Aboriginal and non-Aboriginal academics, activists and practitioners engaged in youth, mental health and climate justice spaces. We argue for structural change to address the causes of the climate crisis, alongside enhanced evidence and approaches to appropriately support the mental health of children and young people. Furthermore, we support the call of Aboriginal peoples to ensure culturally appropriate, place-based responses based in caring for Country.
\end{abstract}

\begin{abstract}
Aboriginal people are the Traditional Custodians of the land on which we walk, work and live. It's important that we recognise their continued connection to the land, sea and community and acknowledge that this connection has extended over 60000 years. Aboriginal people and their culture have continued to survive despite their ongoing trauma and experience by invasion and colonisation. For Aboriginal people in their communities, the impacts of climate change resembles the experiences of colonisation. When the first settlers [Europeans] invaded Australia, falsely and disrespectfully calling it terra nullius, no one's land, they bought with them many strangers carrying many diseases. Today, the man-made impacts of climate change are bringing a new form of disease to our country (Ronda Clarke in Aboriginal Health Council of Western Australia hearing of the WA climate health public inquiry). ${ }^{1}$
\end{abstract}

In 2019-2020, the Western Australian (WA) Government held the world's first climate health public inquiry. ${ }^{2}$ Simultaneously, horrific

Correspondence: Dr Naomi J Godden, Centre for People, Place and Planet, Edith Cowan University - South West Campus, PO Box 1712, Bunbury, WA 6230, Australia. Fax: +61 89780 7800; email: n. godden@ecu.edu.au

Conflict of interest: None declared.

Accepted for publication 2 July 2021 climate change-induced disasters, including bushfires, cyclones, droughts and extreme heat, occurred in WA and across the Australian continent. In response to increased intensity and impacts of climate change, and inadequate government action, young Western Australians have mobilised at a phenomenal pace. The WA School Strike 4 Climate marches in early 2020 (prior to COVID-19 lockdowns) attracted $12000+$ attendees in the capital city (Perth) and regional areas. Young people are keenly aware that 'everything is void if we don't have a planet, if we don't have somewhere to live....? Youth climate activism is justified - globally, children and young people are among the most vulnerable to the health impacts of climate change. ${ }^{4}$ This is due to their 'immature physiological defense systems, the more direct ways they interact with their environment, their dependence on adults, and the accumulation of risks and insults over their lifetimes, ${ }^{5}$

Extensive evidence from the WA climate health public inquiry expresses significant concerns about the mental health impacts of climate change. ${ }^{2,6}$ In particular, children and young people have 'high levels of concern and anxiety about climate change and what their future will look like'. ${ }^{2}$ Indeed, in the 2019 survey of 15703 Australians aged $18-29$ by youth radio station Triple J, 43\% of respondents said climate change was the number one issue affecting their generation, while $22 \%$ of respondents identified mental health. ${ }^{7}$

Furthermore, in their inquiry hearing, the Aboriginal Health Council of WA (AHCWA) highlighted that Western and Aboriginal 
concepts of health are fundamentally different, with Aboriginal health holistically encompassing non-physical elements including family, language, community and Country as well as cultural, spiritual and emotional elements. ${ }^{1}$ AHCWA stated,

When we talk about mental health impacts of climate change, we're talking about the loss and disconnection of our spiritual identity, our cultural beliefs and our values, which are essential requirements for our own lifeforce. ${ }^{1}$

In WA, we can learn from the oldest continuing living culture developed over tens of thousands of years to live sustainably with this environment in ways that decrease risks associated with "natural disasters' like bushfires and adapting to a changing climate. NonAboriginal people have much to learn from Aboriginal cultures. Robertson and Barrow explain that the Nyoongar people in South Western WA have developed a 'value-based, highly cooperative society', which enabled them to use available resources to respond to climate change, including a 10000 year drought. ${ }^{8}$ At the same time, climate change poses multiple threats to Aboriginal and Torres Strait Islander (henceforth Aboriginal) people's wellbeing, exacerbating pre-existing disadvantages in health, education, employment, poverty and incarceration. ${ }^{1}$ (We use the term Aboriginal to refer to Aboriginal and Torres Strait Islander peoples of Australia. We acknowledge that Aboriginal and Torres Strait Islander peoples may identify with their local clans or group name and mean no disrespect in using the collective term Aboriginal. We use the term First Nations to refer to the Indigenous peoples of the world.) The WA climate health public inquiry's final report highlighted the long history of Aboriginal stewardship of WA lands and waters and that this is as critical now as it has ever been. The WA health system must engage and co-design with Aboriginal Elders, peoples, organisations and communities, and respect Aboriginal knowledges and expertise. ${ }^{2}$ For many Aboriginal people, climate change and environmental degradation began with colonisation, which contributes to intergenerational trauma; yet research and solutions rarely focus on this (Box 1).

This article is co-authored by a group of WA young people, Aboriginal and non-Aboriginal academics, activists, and practitioners engaged in youth, mental health and climate justice spaces. The article examines the intersection of mental health, climate change, children and young people and climate activism in WA. We explore the mental health impacts of climate change on children and young people, and youth climate activism as a resilience strategy. In Box 3, youth climate activist co-authors then discuss opportunities to support the mental health of young people compelled to take climate action. We argue for structural change to address the causes of the climate crisis, alongside enhanced mental health evidence and approaches to appropriately support children and young people affected by climate change. Furthermore, we support the call of Aboriginal peoples to ensure culturally appropriate, place-based frameworks and programs based in caring for Country.

\section{The Mental Health Impacts of Climate Change on Children and Young People}

I'm quite worried about my future being destroyed due to climate change. Sometimes, I couldn't sleep - keep thinking of it. I
Box 1 Jason Barrow: Karla Katitjin Wongi (Fire Knowledge Talk) Jason Barrow, a co-author and Nyoongar man reflects on his children's experiences of a recent bushfire.

I had a couple of personal reflections of my own family, my kids, and an environmental incident that happened up here at the end of 2019, where the big fires happened in the edge of national park areas and putting houses under threat. My kids started to freak out that very first afternoon because of their access to social media, and where they got their news from, their information from. And the doses of it, and the continuous and the particular perspective or points of view that were being portrayed and that they had easy access to. And it wasn't until their mum and I... were able to have a constructive conversation with the kids, where I could provide some different points of view about the physical land that they live on, where that fire was travelling through, what climatic conditions were going to come through, and that the fire actually wasn't going to touch their houses, but actually your friend's house over there, they need not to be there in 2 days' time; they need to be gone. That house will be under threat. You guys can come and stay here, you know it's easy, it's closer to school, you are away from that fire, your asthma does not get messed up with the smoke and whatnot.

And when we started to have those household conversations around that, the juxtaposition when they went to school, against their peers, was vastly different, because their peers were not afforded the opportunity with people who had intimate knowledge of the landscape that they were on. I'm not a magic person, but I've lived in this area for the last 35 years, I have grown up here as a young person, I was an Aboriginal Heritage Officer in the National Park, an Education Coordinator, I've studied Environmental Science as well as bringing in a cultural perspective into that area, and I had a number of different tools and attributes that I could bring in, that's in my household. In their mum's household, they had both adult caregivers in that household, one who is actively fighting fires with National Parks, both worked in National Parks so integrated into that landscape and could provide a different level of knowledge and experience around that event. So, the kids had a much better and more resilient perspective and ability around that incident, against their peers.

haven't told anyone about it, 'cause I reckon everyone doesn't seem to care (WA young person). ${ }^{9}$

The mental health impacts of climate change are direct and indirect, and not all impacts are felt equally. Emerging Australian and international evidence suggests that children and young people who are directly exposed to rapid onset extreme weather events (e.g. bushfires, floods, cyclones) and slow-onset extreme weather events (e.g. droughts) are at risk of various psychological effects: feelings of fear, overwhelm, worry, distress, hopelessness and anger; stress; PTSD; depression; anxiety; phobias; panic disorder; sleep disturbances; attachment disorders; learning difficulties; substance abuse; shock and trauma symptoms; adjustment problems; behavioural problems; and, suicidal thinking. ${ }^{10-14}$ Furthermore, level of risk may be amplified by pre- and post-disaster 
factors including pre-trauma circumstances such as personality and coping styles and skills; stage of development; pre-existing vulnerabilities due to Indigeneity, rurality, socio-economic status, gender, sexuality and ability; trauma-related factors such as intensity of the event and proximity and exposure to the event; post-trauma factors such as access to social support and social structure; and, environmental and family context, community disruption and violence. ${ }^{11-15}$

Many children and young people who are not directly affected by climate events express worry, fear, 'ecoanxiety', 'solastalgia', anger, frustration, depression, sadness, grief, anxiety and feelings of powerlessness about the gradual and vicarious impacts of climate change on their lives in the future. ${ }^{9,10}$ Numerous public surveys found that climate change is a significant worry for children and young people in Australia. ${ }^{7,9}$ In the WA Commissioner for Children and Young People's Speaking Out Survey, $42 \%$ of surveyed Year 9-12 students identified mental health and wellbeing as a source of stress in the past 12 months. ${ }^{16}$ As climate change intensifies, the aforementioned mental health risks for children and young people will undoubtedly escalate. ${ }^{14}$ A co-author observes that WA youth mental health services increasingly request frameworks for climate change-related anxieties and stress. To date, policy and practice responses have failed to address the causes of climate change or children and young people's significant health needs. This work must occur within Elder- and community-led frameworks ${ }^{17}$ that protect Aboriginal peoples' cultural and intellectual property.

We identify several trends in the WA climate health public inquiry evidence: (i) Health professionals are seriously concerned about the mental health impacts of climate change on children, young people and Aboriginal peoples; (ii) the WA health sector lacks sufficient evidence about these impacts and about how children and young people cope with climate change as a psychological stressor; and, (iii) there is little understanding of effective interventions and resources to support children and young people, including Aboriginal children and young people - gaps also identified by others. ${ }^{5,10,12,18}$ The intersection of mental health, climate change and children and young people is thus significant for the public health system and society more generally and needs urgent attention.

\section{Youth Engagement in Climate Activism}

There is a significant lack of evidence about how children and young people cope with climate change and effective support mechanisms. $^{4,11,13,18-20}$ A smattering of studies provide some insight. Ojala's research in Sweden about children and young people's coping with climate change found that the more meaning-focused coping the children used the less they experienced negative affect, and the more they experienced life

Box 2 Emma Heyink, WA youth climate activist

I'm involved in activism because it gives you a real sense of power, it feels like you are actually doing something that will help. It's so easy to feel powerless and overwhelmed by the many problems the world is facing and activism is a kind of a relief for that. satisfaction, general positive affect, purpose, and optimism' ${ }^{18}$ In other words, taking climate action helps children and young people feel good, proud, connected to community and hopeful (see also Box 2). Furthermore, de-emphasising the seriousness of climate change is not helpful for environmental efficacy, ${ }^{19}$ while constructive hope is associated with positive environmental behaviour. ${ }^{20}$ Garcia and Sheehan also report that some children and young people develop coping skills and enhanced resilience when exposed to extreme weather events. ${ }^{12}$

Additionally, children and young people engaged in organised action to mitigate the impacts of climate change can manage their anxiety, maintain optimism about the future and have enhanced resilience. ${ }^{5,10,18}$ Sanson and colleagues state, 'Given the evidence that many children feel powerless and hopeless about preventing catastrophic climate change, it is important to build their sense of self-efficacy and collective efficacy'. ${ }^{5}$ It is suggested that resilience for children and young people can occur through individual skills and capacities, interpersonal skills and relationships and social and civic engagement. ${ }^{5}$ The young people co-authoring this article understand there are multiple forms of climate action, and that many young people do not have these opportunities. Some young people are not supported by their families or adults, or have caring responsibilities, and for many, particularly Aboriginal youth and young people of colour, the costs of 'getting into trouble' or missing school are too high.

The escalation of youth climate activism in WA and internationally responds to the very real threat of climate change and inaction. ${ }^{21}$ Some strong examples in WA:

1 School Strike 4 Climate is a climate justice movement led by school students. Students regularly organise strikes from school for peers and adult allies to demand political action to end new fossil fuel projects, enable a just transition to $100 \%$ renewable energy and fund jobs for impacted workers and communities.

2 Millennium Kids Inc is a youth-led environmental organisation that empowers young people to have their say and initiate action projects to address environmental and sustainability issues. Young people explore ways to solve problems through education, education for behaviour change, advocacy, innovation and design, community action and rules and regulations.

3 Climate Justice Union WA is growing a movement of people of all ages taking community-based action for a fair and just transition to net zero emissions, while also supporting communities to prepare for and adapt to climate change impacts. Climate justice involves a transition process of decolonisation, caring for people and place and tackling inequality.

4 Sharma $v$ Minister for Environment: Eight Australian high school students (including a WA student and co-author) launched a legal challenge against the federal Minister for Environment. They successfully argued that the Minister has a duty to protect young people from the devastating impacts of climate change.

In WA, youth climate justice activism occurs in a context of high economic and social dependence upon the resources industry (both metals and fossil fuels), which is mirrored (and secured) by the sponsorship of cultural events. From the 'Woodside Nippers' to the 'Chevron City to Surf', the centrality and visibility of mining within WA influences young people and their engagement in climate activism. Furthermore, undertaking this leadership role may negatively affect children and young people's 
Box 3 Emma Heyink, Eva Carot Collins, Bella Burgemeister and Mena Tabeshfar: Perspectives of WA youth climate activists

Emotional responses: Having a space to be honest and real about what we are feeling

Climate change can be sad and overwhelming for young people, particularly due to our powerlessness to fix the issue. Being involved in climate activist movements can help young people get past feelings of isolation and connect with others who have similar views about climate change. Being involved in collective action like protesting, legal challenges, and strikes can help channel our energy and rage and give us a shared sense of working together for a common goal. At the same time, there is a risk of young climate activists experiencing burnout, especially if we become disenfranchised with the movement and we feel that we aren't having an impact. Youth climate activist groups and networks like School Strike 4 Climate can offer us a shared space to connect with like-minded peers and 'check-in' with each other. It is also important for young people to talk (and rant) about our feelings and experiences with people who support us, like parents, family, friends, and mentors who understand the issues. Humour can also help us diffuse our emotions.

When we learn about climate change in school, we are taught about what we can do at an individual level. This is disheartening because it teaches us that it is our responsibility to resolve climate change, putting more on our shoulders. We also know this is not enough and it will not fix things. Schools do not teach us about different forms of climate action, such as collective action. The way climate change is taught also creates a hierarchy of action. The individual focus means that if young people do not want to commit themselves to all these actions, they do not want to be involved in climate activism. However, we also learn about climate change in activism spaces and on social media. These spaces put the focus and responsibility on governments and people in power. This creates solidarity and community, and we learn that there are many different paths to act on climate change, such as legal routes, protests and lobbying.

It does not help us when there is judgement of young activists. It is seen as uncool to care. We find it hard when other people do not understand or do not care about climate change. At the same time, it makes us angry when people acknowledge the issue and do nothing about it. Sometimes we play it down when promoting action on climate change because we do not want to get a bad reputation. Everyone should be taking climate change very seriously, but we need to balance this - we want to be effective and not lose social collateral. Our society also needs to be open to young people making mistakes, and we need to move away from the judgement of 'purity culture'. It is not helpful to reprimand youth climate activists for little things like using a takeaway coffee cup. We're already juggling a lot - being young, living through climate change and being a climate activist. It also does not help us when people who do not know what they are talking about try to tell us what is happening and make fun of us for it. Youth climate activists are doing what is expected at this time in history, and we need everyone to normalise caring about the environment, and not make it a gimmicky personality trait.

Support at multiple levels and engaging in collective action

We need lots of support across society to care for youth mental health through the climate crisis. This includes individuals, families, communities, services (designed by communities) and policies to support mental health. There are people we can see to talk about mental health issues, but climate anxiety is not considered a mental health issue by the general public. It is hard to support people whose mental health is affected by climate change - you cannot just say 'everything is going to get better', because it is not. We can only really talk to people who understand it. There are not enough appropriate mental health services to support young people, especially in regional areas, and mainstream services are not suited to all young people.

We know taking action can help when we feel despair - but if we do not have support, good mentoring and capacity building opportunities, this action can lead to us burning out. We need adults around us to support our actions and help us be effective. Schools and the education department often tell us we can get in trouble for taking climate action. It would be great if they help us to be effective, find opportunities for us to talk with people that can make a difference, listen when we are angry, and, instead of dismissing us (telling us to stay in school and get good grades so we can get a good job), help us problem solve in a way that makes a genuine difference. We also need to find ways to be connected to Country, to learn from Aboriginal people, to care and understand this place we are living in.

Through our activist peers and our research online, we have learnt that our current system of colonialism, capitalism and exponential growth enables climate change and is getting in the way of us addressing it. In this system, big businesses and fossil fuel industries influence government and policies. Even if we change our individual behaviours, we will still have massive pollution, and people who are poor will still be the most impacted. It can get overwhelming to think we can live without greenhouse gas emissions in this current system, because everything we do will have an environmental impact. We are fighting for system change, which involves lifting the responsibility from individual people to governments for a sustainable future.

As young people, decision-making power is not in our hands, and we can be punished for caring. We need governments to establish a duty of care to protect us from climate change. We can work within the system (such as legal challenges) as well as striking. We can talk to people in power on their level and frequency, and use their tools to make change. The School Strikes and other activism activities are breaking ground for young people in the future, and we have appreciation for everyone who walked before us.

Communicating with each other during and after crises, and being honest about climate change

We need communication about climate change to be clear. Give us the science, not a fancy Paris Agreement name and weird statistics. Too often people think we need to be protected from the information - when what we need is protection from dangerous climate change. We know it is complicated, but we need clarity, transparency, and reality. We want to know what is going on, not political speak. We also need leaders to show us what they are going to do and how they are going to do it, and to be accountable. We need politicians to acknowledge that we are in a crisis and validate how we see the world. We need to see a solid plan to tackle climate change. Politicians say that we are on our way to meeting and beating our Paris commitments. This shifts the focus from solving climate change to only achieving the Paris Agreement, which is not on track with the science. 
Box 3 Emma Heyink, Eva Carot Collins, Bella Burgemeister and Mena Tabeshfar: Perspectives of WA youth climate activists-cont'd

It does not work when the climate debate is distracted by things like overpopulation being the cause of climate change. This derails the entire movement and puts the blame on people who are poor and in the Global South. We have progressed past this point; we cannot blame the climate crisis on poor people who do not emit anything and who are experiencing the worst impacts. The top 10\% of earners contribute the most greenhouse gas emissions, so we need to communicate about capitalism as the cause of climate change and normalise the conversation about climate and capitalism. We need to know how to access a broad range of information and deconstruct it using a systems analysis. As a youth movement, we need to be able to communicate our reality without pressure.

As youth climate activists, we need our peers and adults to normalise caring; normalise collective action; normalise the conversation about colonialism, capitalism and climate change and normalise the truth of the climate crisis. We need them to join us in action.

mental health and familial relationships if not properly supported. A practical framework is needed for youth mental health in the climate crisis, including self-care and preventing burnout for youth activists.

\section{A Framework for Supporting the Mental Health of Young People in the Climate Crisis}

In 2021, Kieft and Bendell published a broad review of psychological literature on crises faced by individuals (e.g. natural disasters, financial crises, terminal illness, terrorism, pandemics, house-fires) to investigate the impact crisis has on mental health and protective measures that can support good mental health through these experiences. ${ }^{22}$ Despite the variety of scenarios investigated, three themes were consistently identified, which provide a framework for supporting mental health through crises. Firstly, supporting emotional engagement of crisis events allowed individuals to process their experiences, leading to post-traumatic growth and capacity to support others through similar experiences. When emotion-focused coping was not utilised, individuals were more likely to develop PTSD and depression. It was noted that children and adolescents were particularly vulnerable to refraining from expressing their emotional experiences to their parents/guardians, to protect loved ones from their own pain. This was different to avoidance - young people were aware of their own emotional experiences but were emotionally isolated. Secondly, mental health could not be solely supported by families and individuals, and a systemic approach from grassroots through to legislation was required. When systemic aspects were overlooked (e.g. adequate mental health policy), the global burden of disease due to mental health increased. Thirdly, transparent and comprehensive communication regarding the crisis was paramount for how individuals navigated the crisis. When communication clearly explained what was to be expected and scaffolded responses prior to the event, disaster-related losses reduced by a half. When communication from governing bodies was not available, individuals sought information from their neighbours.

In response to Kieft and Bendell's framework, ${ }^{22}$ four youth climate activists who are co-authoring this article identify opportunities in Box 3 to support the mental health and wellbeing of children and young people engaged in climate change activism. Given the importance of any work in WA being informed by the knowledges and wisdoms of Aboriginal peoples, and the protective and healing capacity of connection to Country and place, these opportunities must be grounded in Caring for Country, in partnership with and led by Elders and community.

\section{Conclusion}

To support children and young people affected by climate change, WA requires a response that addresses the systemic causes of climate change - colonialism, capitalism and dangerously high emissions while simultaneously strengthening the capacity of parents, adults and youth and mental health sectors to respond to young people experiencing climate change-related stresses. Decolonising our systems must go hand-in-hand with preventing dangerous climate change and supporting mental health, wellbeing, and resilience. As climate events increase in frequency, intensity and duration, mental health services must work with children and young people across cultures to co-design culturally safe and appropriate strategies that support and increase resilience to the psychological impacts of climate change. ${ }^{5,6,10-12,18}$ Interventions must be grounded in the local Country/place, landscapes and culture and be responsive to other local contexts.

Furthermore, we urgently need reliable real-time data about the mental health and wellbeing impacts of climate change on children and young people, and the role of adult support. ${ }^{23}$ Without these data, the health system and policy makers cannot effectively respond to the needs of children and young people, who currently comprise $93 \%$ of the disease burden of climate change. ${ }^{4}$ In WA, services currently lack an evaluated and culturally safe framework for clinical intervention on climate change-driven mental health issues. Such a framework should be grounded in Aboriginal science, knowledges and wisdoms, and the best of Western science; and draw on existing knowledge about community organising, activist wellbeing, navigating vicarious trauma and building community connection as protective factors.

We also identify that methodologies such as Aboriginal Elderand community-led participatory action research (PAR) ${ }^{17,24}$ offer opportunities to conduct climate change research and action in collaboration with Aboriginal and non-Aboriginal young people. Through PAR, young people can develop and implement research questions, methods, actions, and interventions; a best practice approach. ${ }^{25}$ As Spajic and colleagues state, 'Youth have spoken over recent years and their voices only grow louder. It is no longer enough to pursue sustainable development for them, it must be done with them'. ${ }^{25}$ As 'co-researchers' in PAR, young people can also build individual and collective self-efficacy and resilience, and cope with climate-related stress. ${ }^{5}$

The intergenerational injustices of climate change mean that children and young people are most at risk from the climate crisis but have the least power to prevent it. As such, children and young people will continue to mobilise for climate justice. In the 
growing field of climate change and mental health and wellbeing, policy and services must be co-designed with children and young people to provide effective models of support.

\section{Acknowledgements}

NJ Godden is funded by Plan International Australia and Australian Indigenous Leadership Centre. BM Farrant is funded by the Australian National Health and Medical Research Council (Project Grant 1098844). M Blaise is funded by the Australian Research Council (Project Grant DP210101258), Perpetual Ltd and Social Sciences and Humanities Research Council of Canada.

\section{References}

1 Climate Health WA Inquiry Aboriginal Health Council of WA hearing evidence to the Climate Health WA Inquiry. Climate Health WA Inquiry. 2019. Available from: https://ww2.health.wa.gov.au/ /media/ Files/Corporate/general-documents/Climate-Health-WA-Inquiry/PDF/ Transcripts/Aboriginal-Health-Council-WA.pdf [accessed 23 July 2021].

2 Weeramanthri T, Joyce S, Bowman F, Bangor-Jones R, Law C. Climate Health WA Inquiry: Final Report. Perth, Australia: Department of Health; 2020.

3 Pilat L, Cross D. Thousands of Perth protestors demand climate action at global strike. WA Today. 2019.

4 Sheffield PE, Landrigan PJ. Global climate change and children's health: Threats and strategies for prevention. Environ. Health Perspect. 2011; 119: 291-8.

5 Sanson AV, Van Hoorn J, Burke SE. Responding to the impacts of the climate crisis on children and youth. Child Develop. Perspect. 2019; 13: 201-7.

6 Aboriginal Health Council of WA. Submission to Climate Health WA Inquiry. Perth, Australia: Department of Health; 2019. Available from: https://ww2.health.wa.gov.au/ /media/Files/Corporate/general\%20 documents/Climate\%20Health\%20WA\%20Inquiry/public\%20submissions/ Organisations/AboriginalHealthCouncilWA.pdf [accessed 23 July 2021].

7 Triple J. Climate change has replaced jobs and housing as number one issue for young Australians, survey shows. ABC [Internet]. 2019. Available from: https://www.abc.net.au/triplej/programs/hack/whatsup-in-your-world-survey-names-climate-change-top-issue/11525658\#cl imate [accessed 23 July 2021].

8 Robertson F, Barrow J. A review of Nyoongar responses to severe climate change and the threat of epidemic disease-Lessons from their past. Int. J. Crit. Indig. Stud. 2020; 13(2): 123-38.

9 Chiw A, Ling HS. Young People of Australia and Climate Change: Perceptions and Concerns. Western Australia: Millennium Kids Inc; 2019.

10 Burke SEL, Sanson AV, Van Hoorn J. The psychological effects of climate change on children. Curr. Psychiatry Rep. 2018; 20: 35.
11 Carnie T-L, Berry HL, Blinkhorn SA, Hart CR. In their own words: Young people's mental health in drought-affected rural and remote NSW. Aust. J. Rural Health 2011; 19: 244-8.

12 Garcia DM, Sheehan MC. Extreme weather-driven disasters and Children's health. Int. J. Health Serv. 2016; 46: 79-105.

13 McDermott BM, Lee EM, Judd M, Gibbon P. Posttraumatic stress disorder and general psychopathology in children and adolescents following a wildfire disaster. Can. J. Psychiatry 2005; 50: 137-43.

14 Xu Y, Wheeler SA, Zuo A. Will boys' mental health fare worse under a hotter climate in Australia? Popul. Environ. 2018; 40: 158-81.

15 Parkinson D, Farrant BM, Duncan A. Women and children. In: Walker R, ed. Climate Change Adaptation for Health and Social Services. Clayton, Australia: CSIRO; 2015.

16 Commissioner for Children and Young People. Speaking Out Survey 2019. Western Australia: CCYP; 2020.

17 Farrant BM, Shepherd CCJ, Michie C et al. Delivering elder- and community-led aboriginal early childhood development research: Les sons from the Ngulluk Koolunga Ngulluk Koort project. Children (Basel, Switzerland) 2019; 6: 106-120.

18 Ojala M. How do children cope with global climate change? Coping strategies, engagement, and well-being. J. Environ. Psychol. 2012; 32: $225-33$.

19 Ojala M. Regulating worry, promoting Hope: How do children, adolescents, and young adults cope with climate change? Int. J. Environ. Sci. Educ. 2012; 7: 537-61.

20 Ojala M. Hope in the face of climate change: Associations with environmental engagement and student perceptions of teachers' emotion communication style and future orientation. J. Environ. Educ 2015; 46: 133-48.

21 Clark H, Coll-Seck AM, Banerjee A et al. A future for the world's children? A WHO-UNICEF-Lancet Commission. Lancet 2020; 395 : 605-58.

22 Kieft J \& Bendell J The responsibility of communicating difficult truths about climate influence societal disruption and collapse: An introduction to psychological research. Institute for Leadership and Sustainability Occasional Papers. 2021; 7. Available from: https://insight. cumbria.ac.uk/id/eprint/5950/1/Bendell_occasionalpaper7b.pdf [accessed 23 July 2021].

23 Shier $\mathrm{H}$. Empowerment of Children and Adolescents: What Is it, how Does it Occur, and What Is the Adult supporter's Role?: Children's Research Network; 2019.

24 Godden NJ, Macnish P, Chakma T, Naidu K. Feminist participatory action research as a tool for climate justice. Gend. Dev. 2020; 28 : 593-615.

25 Spajic L, Behrens G, Gralak S, Moseley G, Lindolm D. Beyond tokenism: Meaningful youth engagement in planetary health. Lancet Planet. Health 2019; 3: e373-e5. 